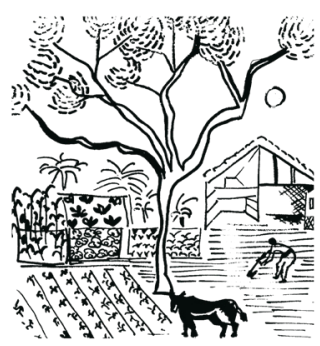

\title{
A contradição entre os sistemas produtivos camponeses e o agronegócio no Assentamento Celso Furtado, no município de Quedas do Iguaçu- PR
}

Elder José Marcelites ${ }^{1}$ Pedro Ivan Christoffoli ${ }^{2}$

ReSumo: O texto busca problematizar os processos produtivos dos camponeses assentados no Assentamento Celso Furtado no município de Quedas do Iguaçu-PR, e as ações do agronegócio nesse território. Parte-se do pressuposto de que as estratégias de resistência e reprodução social difundida pelo Movimento dos Trabalhadores Rurais Sem Terra (MST) potencializam e reforçam a perspectiva de um modelo de desenvolvimento que contribui para a permanência dos agricultores em áreas de reforma agrária. Nesse sentido, a contradição nos processos produtivos do assentamento torna um território em disputa, pois a luta camponesa não termina com a conquista da terra. $\mathrm{O}$ artigo faz parte de pesquisa em andamento e foi resultado da dissertação de mestrado.

Palavras-Chave: Assentamento; Contradições; Desenvolvimento; MST.

THE CONTRADICTION BETWEEN PEASANT PRODUCTIVE SYSTEMS AND AGRIBUSINESS IN THE CELSO FURTADO Settlement, IN THE Municipality OF Quedas do IguaÇU - PR

Abstract:The effort of this text is to problematize the productive processes of the peasants settled in the Celso Furtado settlement in the municipality of Quedas do Iguaçu-Pr, and the agribusiness actions in that territory. It is assumed that the strategies of resistance and social reproduction disseminated by the Movement of Landless Rural Workers (MST), strengthens and reinforces the perspective of a development model that contributes to the permanence of farmers in areas of agrarian reform. In this sense, the contradictions in the productive processes of the settlement, makes a territory in dispute, because the peasant struggle does not end with the conquest of the land.

KeYwORDS: Rural Settlements; Contradictions; Development; MST.

\footnotetext{
${ }^{1}$ Mestre em Agroecologia e Desenvolvimento Rural Sustentável do Programa de Pós-graduação da Universidade Federal da Fronteira Sul (UFFS). E-mail: eldermarcelites@yahoo.com.br

${ }^{2}$ Docente no Programa de Pós-graduação em Agroecologia e Desenvolvimento Rural Sustentável da Universidade Federal da Fronteira Sul (UFFS). E-mail: pedroivanc@uffs.edu.br
} 


\section{INTRODUÇÃ̃o}

O Assentamento Celso Furtado é fruto de luta do Movimento dos Trabalhadores Rurais Sem Terra (MST), desde a década de 1990, em oposição ao latifúndio controlado pela empresa Araupel ${ }^{3}$. Através das ações de enfrentamento ao modelo agroexportador de commodities, o movimento tem proposto novas relações sociais e produtivas na área.

Neste embate, verifica-se um conjunto de intervenções que se erguem como parte das estratégias de resistência e expansão de ambas as perspectivas de desenvolvimento. De acordo com Fernandes (2008), o território do campesinato e do agronegócio são distintos, possuem relações sociais diferentes e modelos divergentes, estando, portanto, em constante disputa pela territorialização de suas relações.

Do ponto de vista da teoria marxista, as relações sociais estão intimamente ligadas à propriedade sobre os meios de produção e à força de trabalho que estabelecem a divisão da sociedade, tanto que ao mudarem as relações de produção, os homens estabelecem novas relações sociais históricas. Há um contínuo movimento de crescimento das forças produtivas e ao mesmo tempo de destruição, de transformação das relações sociais, assim a produção das riquezas resulta desse antagonismo, concomitantemente em que se desenvolvem as forças produtivas, desenvolve-se também o antagonismo das classes (MARX, 1983). Nesse sentido, ao olhar para o Assentamento Celso Furtado e compreendê-lo é necessário analisar as múltiplas determinações que caracterizam o movimento da história do mesmo. $\mathrm{O}$ antagonismo de classes proposto por Marx tem a ver com as múltiplas determinações que caracterizam a história do assentamento.

Com a conquista de uma fração do latifúndio em 2005, os trabalhadores rurais tentam implementar num primeiro momento sistemas produtivos de acordo com suas especificidades culturais, econômicas e sociais. Entretanto, com o passar dos anos esta condição se modifica com o desenvolvimento das estruturas produtivas do agronegócio e os limites e contradições do projeto camponês, onde a possibilidade de recriação do campesinato é enfrentada e reapropriada pelo capital. As estratégias produtivas subordinadas ao agronegócio alteram não somente os sistemas de produção inicialmente propostos, mas também tensionam as relações entre as famílias assentadas, provocando novas divisões entre elas.

Nesse sentido, o trabalho propõe contribuir com o debate sobre as condições

\footnotetext{
${ }^{3}$ A empresa Araupel (antiga Giacometti-Marodin), com sede operativa em Quedas do Iguaçu - PR, se constituía no maior latifúndio do sul do Brasil, com abrangência territorial de mais de 80 mil hectares praticamente contíguos, espraiados em 5 municípios da Região Centro Sul do Paraná. A propriedade dessas áreas hoje se encontra sob questionamento judicial, já tendo sido realizado o assentamento de mais de 3 mil famílias pelo INCRA, a partir das lutas dos camponeses organizados pelo MST.
} 
materiais de existência camponesa, desde a conquista da terra, até aquelas travadas no interior do assentamento, ainda que em si, não desenvolva uma análise aprofundada sobre as formas como o capital se apropria da mais valia gerada pelo trabalho camponês nesse assentamento.

Para isso, buscou-se utilizar recursos metodológicos de aproximação e reflexão mais próxima possível do contexto real, amparado pelo movimento histórico como prática social do ser humano expressado nas relações sociais de produção. Nesse pressuposto, pautou-se pela realização de entrevistas semi estruturadas com sujeitos que mantém envolvimento no contexto histórico de participação no processo de conquista e consolidação do assentamento. Dessa forma buscou-se contextualizar as análises e decisões tomadas pelos camponeses, bem como suas percepções sobre as contradições que foram surgindo ao longo da linha do tempo de implantação e consolidação do assentamento.

\section{O Campesinato Sob a luz Da Teoria Social}

As estratégias de reprodução do campesinato enquanto condição de recriação permanente, sempre foram temas de distintas análises e interpretações teóricas. $\mathrm{Na}$ medida em que o sistema capitalista de produção se desenvolve surgem novas formas sociais de organização do campesinato como sendo resultado da modernização das relações no campo pela industrialização da agricultura, e até mesmo o seu desaparecimento (LÊNIN, 2014; KAUTSKY, 1980).

Kautski analisa a questão agrária a partir da Alemanha num período de transformação do modelo de sociedade no final do século XIX, e identifica o processo de industrialização da agricultura pela indústria, com a consequente substituição da pequena pela grande propriedade agrária. Dessa forma, as atividades agrícolas camponesas perderiam sua especificidade, pois o progresso técnico industrial capitalista promoveria a destruição de parte das atividades produtivas camponesas, bem como a introdução de sistemas de mediação mercantil da produção e dos insumos crescentemente utilizados pelos agricultores, o que levaria à introdução da monetização em substituição à produção autárquica de ferramentas, utensílios e vestimentas.

Contemporâneo a Kautsky, Lênin (2014) estuda os processos de transformação da agricultura na Rússia Czarista e nos EUA, onde identifica a introdução gradual de relações capitalistas de produção na agricultura, levando a uma diferenciação interna entre os camponeses. Uma parte deles passa a adotar técnicas e insumos industriais, adquiridos no mercado, sujeitos a relações de produção capitalistas. Essa relação força a introdução das mediações de mercado, rompendo com a autarquia das comunidades rurais e gerando processos de assalariamento ou de introdução 
de insumos adquiridos externamente às unidades e às tradicionais comunidades rurais. Outra parte dos camponeses perde as terras e se converte em assalariados rurais, ao passo que outros ainda conseguem conservar suas terras, entretanto têm que pagar taxas aos latifundiários feudais (caso da Rússia) ou sujeitar-se ao trabalho parcial fora das suas terras para complementar a baixa renda obtida com o trabalho camponês.

Daí então que a difusão dos instrumentos aperfeiçoados associados a expropriação dos camponeses, são fenômenos estreitamente ligados entre si. Conforme destaca o autor, as máquinas são acessíveis somente aos grandes proprietários, pois implicam elevados capitais, as quais só se amortiza com um imenso volume de produção. $\mathrm{O}$ emprego das tecnologias gera concentração da produção e da cooperação capitalista na agricultura.

Elaborada num contexto de debate sobre o papel do campesinato na Rússia, "A Organização da Unidade Econômica Camponesa" de Chayanov (1974), o autor demonstra as diferentes formas pelas quais as unidades camponesas alcançavam o equilíbrio e a organização dos grupos familiares. Na teoria do balanço entre trabalho e consumo, relata a necessidade de a família orientar suas atividades num sentido de aproveitar ao máximo a força de trabalho, inclusive evitando períodos de ociosidade. Nessa lógica, o grau de intensidade dessas atividades econômicas, manteria íntima relação com os membros capacitados da família. Pela inviabilidade da adoção de máquinas pelos custos de aquisição, manutenção e principalmente da disponibilidade de terra, Alexander Chayanov argumenta que o único caminho para a interferência sobre as unidades produtivas camponesas seria o cooperativismo, uma forma eficaz de competir numa estrutura de mercado consolidada sob o controle das grandes corporações, o que poderia viabilizar o aumento e qualidade da produção por meio da organização coletiva do trabalho.

Partindo da premissa da compreensão das raízes históricas da questão agrária no Brasil, Caio Prado Jr (1981) parte do pressuposto de que o alto grau de concentração da propriedade fundiária conduziu à pobreza e a exclusão do trabalhador rural. A forma como ocorreu a organização agrária sendo baseada na concentração das terras e do poder, manteve o campesinato à margem do progresso no campo em conseqüência das relações de trabalho centradas na escravatura, com uma pequena mudança após o assalariamento.

Diferentemente da Europa que passou pelo sistema feudal, o desenvolvimento do campo brasileiro pautou-se no latifúndio, mão-de-obra escrava e a monocultura. Então, o caminho viável para o desenvolvimento do campo no Brasil seria a superação dessas relações obsoletas, com a elevação dos padrões de vida da população rural vinculada a realização da Reforma Agrária e da proteção legal ao 
trabalhador rural.

Outro importante estudioso da questão agrária brasileira, Martins (1981) também parte do entendimento de que a exclusão do campesinato é uma conseqüência do processo histórico. No entanto, para ele a existência de uma classe camponesa não se constituiu a partir de um resquício feudal, e nem pode ser reduzida à condição de assalariada. A restrição do direito a terra com a Lei de Terras de 1850 e o declínio do trabalho escravo, o campesinato muda de forma quando as grandes propriedades subjugam a mão-de-obra livre. Nesse sentido, Martins (1981) relata que a formação da classe camponesa brasileira ocorreu com a transformação da terra em mercadoria, restando-lhes apenas a posse precarizada. Nessas circunstâncias, a produção camponesa é subjugada pelo capital que impõe preços e tributos pelo uso do solo agrícola, numa lógica de expansão capitalista no campo.

Com o desenvolvimento de novas estruturas produtivas a partir de meados do século XX sob a égide do modelo tecnológico de integração da economia urbana ao campo, os sistemas produtivos do campesinato sofreram fortes reveses. De acordo com Delgado (2012), o controle do setor agrícola ocorreu através do pacto agrário modernizante de integração técnica da indústria com a agricultura. Arquitetado pela aliança das oligarquias rurais, pelo capital financeiro e pelo Estado, a modernização conservadora desencadeou um processo intensivo de utilização de agroquímicos de fertilizantes e de sementes híbridas no campo. Na busca constante pela maximização dos lucros e a apropriação dos recursos naturais, o modelo de desenvolvimento agroindustrial promoveu mudanças nos sistemas produtivos do campesinato.

Paradoxalmente, a expansão do capitalismo no campo não eliminou por completo a produção camponesa. Conforme Oliveira (2001), na agricultura o capital atua no sentido de criar e recriar as condições para que o campesinato constitua um modo específico de produção, visando à usurpação da renda da terra. No mesmo momento em que o sistema impõe relações de trabalho assalariado e concentra riqueza pela expulsão do campesinato, contraditoriamente possibilita a criação de relações não necessariamente capitalistas como é o caso da produção camponesa. Nessa lógica, a reprodução ampliada do capital ocorre por meio da articulação dessas distintas relações de produção.

Diante das circunstâncias pelas quais o campesinato é submetido, Abramovay (2012) não vislumbra nenhuma ascensão social da classe a não ser pela via do próprio sistema. Para o autor, a única alternativa viável seria a integração por completo ao capital, transformando-se em agricultores familiares modernos regidos pelas leis mercadológicas, caso contrário a expropriação do campesinato seria uma condição inevitável devido sua dificuldade de competir no mercado.

No entanto, independentemente dos pressupostos teóricos que vislumbram no 
capital a possibilidade de recriação do campesinato, a história da classe camponesa é marcada de luta e resistência. Com o colapso do período ditatorial houve uma retomada das condições necessárias para que os movimentos sociais camponeses pudessem colocar em pauta política e na sociedade a importância da Reforma Agrária para o país, como é o caso do MST. Através das ocupações de terras e a conquista de assentamentos rurais, o Movimento dos Trabalhadores Rurais se constituiu como o principal protagonista de recriação do campesinato a partir da sua criação em 1984.

No Paraná, as principais lutas que ocorreram a partir de 1990 envolvendo o MST versus latifúndio concentraram-se na Mesorregião Centro-Sul ${ }^{4}$, onde o Assentamento Celso Furtado foi criado em 2005, sendo fruto dessas lutas. No próximo item, o trabalho aborda a formação das estruturas produtivas no assentamento e as conseqüentes relações sociais constituídas, procurando dialogar com as abordagens teóricas discutidas no texto.

\section{AS RELAÇões SOCIAIS DE PRODUÇÃo NO ASSENTAMENTO}

Criado no ano de 2005 mediante a PORTARIA/INCRA/SR(09)/N² 20/2005, e publicada no Diário Oficial da União de 05 de Outubro de 2005, o Assentamento Celso Furtado com 1.095 famílias assentadas numa área de 23.733,58 hectares ${ }^{5}$, ocorreu num período de expansão das relações capitalistas no campo, por outro lado, paradoxalmente numa conjuntura favorável às lutas camponesas nessa região.

Porém, a carência ou mesmo a desproporcionalidade dos recursos financeiros do Estado para a reforma agrária, abre espaço para a atuação de sistemas produtivos que não proporcionaram autonomia aos novos assentados. Embora que no Plano de Desenvolvimento do Assentamento (PDA) constassem os projetos que seriam executados, estes permaneceram dependentes em muito do amparo inexistente de políticas públicas. Sendo assim, apesar das ações e práticas políticas do MST que permitiram a conquista da área, a proposição das estratégias de resistência na terra, limitou-se a uma expectativa de controle futuro do processo de agroindustrialização e comercialização, o que permitiu ao capital por sua vez a continuar diuturnamente realizando a extração da renda da terra por meio da expropriação de parcela significativa da produção dos assentados.

\footnotetext{
${ }^{4}$ DeacordocomoINCRA(2018), aMesorregiãoCentro-SulconcentraomaiornúmerodefamíliasassentadasdoEstadodoParaná,mas também dos maiores conflitos agrários. Disponível em: http://painel.incra.gov.br/sistemas/Painel/ImprimirPainelAssentamentos. php?cod_sr=9\&Parameters\%5BPlanilha\%5D=Nao\&Parameters $\% 5 B B o x \% 5 \mathrm{D}=$ GERAL\&Parameters $\% 5 \mathrm{BLinha} \% 5 \mathrm{D}=$. Acesso em: 23 de outubro de 2018.

${ }^{5}$ Informações baseadas na Cooperativa de Trabalhadores em Reforma Agrária (COOTRARA), a instituição responsável pela elaboração do Plano de Desenvolvimento do Assentamento (PDA), e da assistência técnica e extensão rural das famílias assentadas no assentamento Celso Furtado.
} 
Tomando como referência as principais tipologias produtivas adotadas no assentamento, a produção de grãos é uma das atividades mais praticadas pelos assentados, pois se destina tanto para o comércio, como também para suprir as necessidades de consumo das famílias, o que significa que há uma hierarquia dessas atividades agrícolas desenvolvidas nos lotes, em áreas de proporções diferentes, dependendo da importância atribuída pelo agricultor. Entre essas culturas é perceptível a hegemonia da soja, ao passo que a produção de feijão e milho é secundária.

Em entrevista com um assentado que produz para o mercado e para o consumo da família, ele relata que, para sobreviver do lote é preciso realizar várias atividades, assim quando alguma delas não alcança suas expectativas, pode outra dar um retorno financeiro maior. Desprovido de técnicas modernas de produção, contrata serviços de horas máquinas na realização da lavoura comercial enquanto que as culturas que se destinam à subsistência utilizam equipamentos manuais. "Eu produzo aqui feijão, milho pra consumo né, é planto soja também, é isso o que garante nossa subsistência no lote. [...] Parte eu faço com máquinas, máquinas contratadas pra fazer né, pago por hora pra fazer isso, e partes é manual mesmo (Assentado 1 , julho de 2018).

Por isso, as culturas que se destinam exclusivamente ao comércio predominam entre os produtores que se utilizam de máquinas próprias, diferentemente daqueles que não possuem. Nessa lógica, a produção da soja e do trigo, por exemplo, que visam o comércio pressupõe a utilização de maquinários, fertilizantes, agrotóxicos e sementes industrializadas. Por vez a produção de milho e feijão que possuem uma dupla funcionalidade, quer dizer para o comércio, mas também alimento de animais e pessoas que compõem o grupo familiar, estas se destacam entre os produtores que se utilizam em suas unidades produtivas instrumentos mais simples de produção, desde as manuais, na cooperação pela troca de dias de serviços, e quando muito contratando serviços de horas máquinas de quem as possui.

Nestas relações produtivas desiguais, as culturas que necessitam de agroquímicos e de mecanização tornam-se atividades desproporcionais as pequenas unidades produtivas. Para tanto, uma pequena parcela de agricultores que apresentam condições de produção mais estruturadas, arrendam lotes de outros assentados para produzir geralmente culturas que se destinam ao mercado como é o caso principalmente da soja. Nessa lógica, as relações contraditórias de produção no assentamento tornam-se ainda assim uma alternativa para as famílias, todavia de forma precarizada e sob a manutenção dos camponeses a margem desse modelo de desenvolvimento (MARTINS, 1981). 
Da mesma forma, a produção orgânica do assentamento, que de início contava com 109 produtores organizados em dois grupos, um com 22 e outro com 87 famílias, chamou a atenção de diversas organizações que defendem essa bandeira haja visto o número significativo de produtores interessados, mas sobretudo das experiências que estas poderiam contribuir na construção da agroecologia na região. Porém a burocracia na liberação dos recursos disponíveis, aliado a falta de assessoria técnica continua, e de investimentos estruturantes da comercialização levaram ao desestímulo dos agricultores.

Embora uma pequena parcela de produtores consiga ainda hoje produzir excedentes, sem um mercado consumidor organizado, o resultado das vendas segue os mesmos padrões dos convencionais, acabando por comprometer a produção orgânica. Ainda que haja organizações produtivas em formas de brigadas e associações, estas objetivam a obtenção de máquinas e equipamentos agrícolas para o plantio principalmente culturas que se destinam na transformação de alimentos para o rebanho de gado leiteiro, como é o caso de silagem.

Na pecuária leiteira, a subordinação da renda da produção camponesa ao capital dá-se por várias formas. Sendo a atividade realizada em praticamente todas as unidades produtivas, como a principal fonte de renda. A produção leiteira teve ponto de partida no período de prestação de serviços de Assistência Técnica e Extensão Rural (ATER) desenvolvidas por entidades como o Centro de Desenvolvimento Sustentável e Capacitação Agroecologia (CEAGRO) em convênio com o Instituto Nacional de Colonização e Reforma Agrária (INCRA). Os produtores tiveram contato com novas técnicas principalmente da utilização do método de Pastoreio Voisin (PRV) e da alimentação de animais a base de pasto, suplementado por silagem produzida localmente, o que possibilitou aumento significativo na produção, tornando assim a atividade econômica mais praticada pelos assentados, em raros casos são os lotes que o leite é suplementar as demais.

No entanto, ao passo que houve aumento produtivo, há uma demanda de tecnologia na produção e armazenamento. Ao mesmo tempo em que a pecuária do leite é a atividade mais realizada pelos assentados, é também a que mais subordina a produção ao capital industrial e comercial por meio dos cuidados zoossanitários e nutricionais dos animais. Com a necessidade de alimentar o rebanho no período de inverno, surgem despesas de insumos e horas máquinas no plantio e na transformação do milho em silagem. Adicionado a essas despesas, verifica-se o uso de fontes de alimentos de origem industrial como é o caso da ração e sal mineral, e de medicamentos veterinários. Com relação aos cuidados fitossanitários, o capital industrial absorve outra parte significativa da renda da produção camponesa pela 
busca constante da padronização da produção.

Porém, a comercialização ainda é realizada em vários laticínios da região em forma in natura resultando em baixos preços. De acordo com nossa interlocutora que está na atividade desde que foi assentada, relata que a produção no assentamento tem destino às agroindústrias de várias cidades próximas, ficando apenas uma pequena parte no município.

[...] Nós vendemos a produção do assentamento em vários municípios da região, seja Cantagalo, Laranjeiras do Sul, Cruzeiro do Iguaçu, agora também em São Jorge do Oeste, Catanduvas, Cascavel, então são vários laticínios que coletam leite aqui, visto que a produção é uma produção grande no assentamento, então um só não tem condições de absorver, no município fica muita pouca coisa, a maioria vai para fora do município mesmo (E. C. R. Assentada e produtora de leite, julho de 2018).

As agroindústrias que comercializam a produção de leite exercitam transferência de renda das pequenas unidades produtivas ao capital industrial. Numa condição pré-estabelecida aos agricultores que se aventurariam na atividade, o investimento constante em tecnologia é o ponto necessário, tendo em vista que a produtividade conciliada com a qualidade do produto são cada vez mais exigidas na cadeia produtiva.

Vale ressaltar ainda que os preços estabelecidos variam de produtor para produtor de acordo com os volumes e qualidade de produção. Numa estratégia de forçálos os a se adequarem às suas exigências, as indústrias lácteas aplicam preços diferenciados, onde quem produz menos de certa forma é penalizado, por outro lado beneficia quem produz maior volume. Assim, existe uma diferença de valores pagos por quantidade produzida, mas também pela qualidade (teor de gordura e acidez). Da mesma maneira, é indispensável acrescentar que a matéria-prima ao entrar no circuito mercantil assume o caráter de mercadoria, estando, portanto submetida às variações de preço decorrentes da dinâmica do mercado. Todos esses fatores afetam a rentabilidade e a sustentabilidade dessa cadeia produtiva.

Diante do exposto, a inserção da matéria-prima produzida no assentamento ao circuito mercantil, é parte integrante da subordinação às agroindústrias da região. Nesse sentido, a importância outorgada pelos trabalhadores à pecuária leiteira deve-se pela dependência econômica dos assentados e à renda mensal propiciada pelo leite, no entanto também ilustra o grau de dependência frente às relações capitalistas no campo.

Outra atividade agrícola que tem sido uma opção de trabalho e renda as 
famílias, é a integração a indústria do tabaco, que gera ocupação aos membros do grupo familiar numa área de cultivo relativamente reduzida, sem comprometer o desenvolvimento de outras atividades. Uma atividade quase que exclusivamente vinculada à agricultura de base familiar, o sistema não expropria os meios de sobrevivência do camponês pela posse da terra (porque não lhe é vantajoso, frente a uma alternativa baseada no assalariamento pleno dos trabalhadores), mas subordina a sua produção à indústria numa relação de troca desigual.

Embora o agricultor seja detentor e produtor dos seus meios de produção, está sujeito às regras socioeconômicas complexas, não tendo controle do processo produtivo e comercial, haja vista que é totalmente determinado pelo capital. Assim, a integração visa a compra da produção pelas indústrias, as quais interferem diretamente no processo de produção através do fornecimento de insumos, tecnologias e assistência técnica, onde os produtores são submetidos a regras e garantias estabelecidas pelas empresas integradoras.

Nesse sistema, os produtores assumem a obrigatoriedade do pagamento dos débitos no momento da entrega na forma de produção, sem a necessidade de dispêndio monetário. Em entrevista, um produtor relatou que depois de alguns anos de trabalho integrado há uma maior facilidade para obter financiamentos com a referida empresa fumageira.

A empresa vem aqui na casa, nós fazemos o pedido para começar a plantar. Aí eles trazem todos os insumos e nós plantamos. Só ligar e eles vem buscar a produção aqui e depositam o dinheiro na conta. É tipo integração, nós não nos viramos com nada, só com o trabalho (A. J. Assentado e produtor de fumo, julho de 2018).

Ao assumirem o papel de agentes financiadores, as empresas determinam as taxas de juros e preços dos insumos, mas, sobretudo do preço da arroba ${ }^{6}$ do fumo. Assim, mais que atuar na industrialização também pratica a usurpação da renda da terra em duas situações distintas no mesmo setor produtivo.

Porém, do ponto de vista de nosso interlocutor, a fumicultura nos últimos anos tem sido uma importante atividade econômica de sobrevivência da família no lote. Com um ciclo de quatro a cinco meses, não compromete outras atividades agrícolas, mas, sobretudo da ocupação dos membros familiares (força de trabalho disponível) é um dos critérios relevantes na tomada de decisões para o cultivo do tabaco. Nosso interlocutor relata que várias atividades foram experimentadas,

${ }^{6}$ Uma arroba equivale a 15 quilos. 
porém a cultura do fumo se adaptou melhor no lote tendo em vista o tamanho e limites da propriedade.

Nos primeiros anos nós plantamos feijão mas não deu certo, aí começamos com vaca de leite também. Como meu lote é pequeno, tipo assim três alqueires, o resto é mato e banhado, aí vendi as vacas e começamos com o fumo, que é o que menos ocupa terra, pouco quadro né, em meio alqueire você pode tirar por quatro a cinco de soja. Plantamos soja, milho, feijão, um pouco pro gasto e o fumo, é o que mais ... rende em dinheiro pra nós; ... no ano passado sobrou 23 mil e sobrou limpo, né. Esse ano deu muita chuva sobrou menos, sobrou só 10 mil limpo, fora os insumos, as despesas de plantar, né. (A. J. Assentado e produtor de fumo, julho de 2018).

Apesar das intempéries relatadas pelo interlocutor, o cultivo do fumo é compreendido como uma fonte de renda e ao mesmo tempo geradora de trabalho. Ou seja, uma possibilidade de manutenção e reprodução da família no lote mesmo que num determinado sistema produtivo de perda da autonomia camponesa.

Do ponto de vista dos autores que defendem a integração das pequenas unidades produtivas onde o trabalho e a propriedade estão ligados a família, o sucesso econômico destas depende diretamente do grau da sua integração com a lógica capitalista de produção. Nessa corrente teórica, as profundas mudanças que ocorreram na sociedade no final do século XX afetaram as formas de produzir dos agricultores, adaptando-os ao mercado que por vez responderam às exigências dos novos contextos que são submetidos (ABRAMOVAY, 1993).

Ainda que o trabalho familiar seja uma realidade na produção de tabaco, uma explicação teórica mais condizente com a realidade diz respeito à centralidade ou objetivo principal da produção camponesa que é a garantia da existência e da reprodução social do grupo. Portanto, a efetivação da relação de troca de mercadorias com o mercado que nesse caso é a matéria-prima para a indústria visa uma reprodução simples, o que significa dizer que a família repõe a cada ciclo da atividade produtiva, os meios necessários de sobrevivência ao contrário da empresa integradora que tenciona a reprodução ampliada do capital.

Partindo dessa assertiva, Oliveira (2007) relata que no atual estágio monopolista, o sistema cria e recria relações capitalistas visando a sua reprodução ampliada permanente, seja pela expansão do capital no campo pela compra e venda da terra, e também pela subordinação da produção camponesa. Nesse sentido, embora que a família produtora de fumo ainda tenha a posse da terra, sua reprodução social está sujeita às regras impostas pelo desenvolvimento desigual e contraditório do 
capital. O sistema de integração situa-se nesse processo como uma maneira de integrar a produção camponesa nos mercados competitivos voltados à exportação, porém contraditoriamente mantém os agentes diretos de produção a margem desse modelo de desenvolvimento.

Nessa relação econômica desproporcional, as empresas não abrem mão da taxa de lucro por meio do controle total do processo produtivo, desde os financiamentos que estão embutidos as taxas de juros pagas em forma de produção, mas principalmente do preço final da matéria-prima independentemente das condições econômicas ou físicas dos produtores no resultado final dessa operação. Por isso, a integração do agronegócio da fumicultura no assentamento tem gerado um modelo de desenvolvimento contraditório e desigual na medida em que uma parcela significativa da renda da produção camponesa é absorvida pelas empresas integradoras, conseqüentemente dispondo a maioria dos produtores quase sempre a marginalização, com raras exceções os que conseguem se integrar num sentido irrestrito da palavra.

Portanto, a busca de reprodução social dos camponeses é condicionada pelas relações capitalistas de produção que ora se apresentam como uma alternativa ao desenvolvimento do capital, ora como formas de resistência enquanto condição de manutenção dos grupos familiares no campo. Então as contradições permeadas são fruto do próprio sistema, onde as estratégias de luta constituem possibilidades de existência e de autonomia ainda que relativa frente ao sistema de produção, sabendo-se que diante do atual estágio que se encontra despir-se por completo dele é uma tarefa muito difícil, senão impossível.

\section{CONSIDERAÇões FINAIS}

Evidentemente esta é uma análise parcial e incompleta diante da complexidade das lutas dos camponeses do Assentamento Celso Furtado. Compreender o movimento da realidade necessita de aprofundamentos e de atualizações permanentes.

Partindo desse pressuposto, é importante destacar que num primeiro momento o projeto defendido pelo MST foi vitorioso ao derrotar o latifúndio da Araupel, no entanto posteriormente o desenvolvimento das estruturas produtivas ocasiona relações sociais de produção contraditórias e até mesmo antagônicas. A escassa efetividade da atuação do Estado referente à implantação de infraestrutura produtiva e de prestação de serviços acarreta o avivamento dessas contradições. Então há um embate político entre o movimento camponês e o Estado por políticas públicas para o campo.

Essas relações ocultas pela apropriação e uso do território, expressam relações 
de poder, reforçando assim a definição das configurações do assentamento, proveniente das disputas entre classes sociais que tentam apropriar-se do espaço para nele constituir projetos territoriais. Esse delineamento estabelecido pelas relações capitalistas, pode-se afirmar ser em grande medida originário das políticas públicas para as áreas de assentamentos, implantadas de forma verticalizada, onde os camponeses são submetidos a própria sorte no mercado competitivo e desigual, ainda mais num período em que as perspectivas de desenvolvimento para o campo tende a privilegiar o modelo produtivista do agronegócio.

\section{REFÊRENCIAS}

ABRAMOVAY, Ricardo. Paradigmas do capitalismo agrário em questão. 3 ed., $1^{\mathrm{a}}$ reimpressão. São Paulo, SP: Edusp, 2012. 294p.

ASSENTADO 1. Entrevista gravada em julho de 2018.

CHAYANOV, Alexander V. La organización de la unidad económica campesina. Buenos Aires: Nueva Visión, 1974.

DELGADO. G. C. Do "capital financeiro na agricultura" a economia do agronegócio: mudanças cíclicas em meio século (1965 - 1985). Porto Alegre: Editora da UFRGS, 2012.

LENIN, Vladimir, Ilitch. O desenvolvimento do capitalismo na Rússia. O processo de formação de mercado interno para a grande indústria. Tradução e interpretação de José Paulo Netto. Abril Cultural. São Paulo, 1982. In: Coletâneas de textos da ENFF n ${ }^{\circ}$ 03. Teorias do Desenvolvimento do Capitalismo na Agricultura. Outubro de 2010, atualização em abril de 2014.

MARTINS, José de S. Os camponeses e a política no Brasil. Petrópolis: Vozes, 1981.

OLIVEIRA, Ariovaldo, Umbelino. A agricultura camponesa no Brasil. 4. ed. São Paulo, SP: Contexto, 2001. 164p.

KAUTSKY, Karl. A questão agrária. 3. ed. São Paulo: Proposta Editorial, 1980. 